\title{
Trachnology
}

\section{Retaining Master Gardener Volunteers}

Larry Stouse' and

Charles Marr $^{2}$

Additional index words. cooperative extension, horticulture, gardener training

Summary. Master Gardeners are volunteers who assist local cooperative extension horticulture and related program efforts by receiving training and conducting educational activities and projects. Participants generally receive training and volunteer within a l-year period. The emphasis has shifted to longer retention of trained, experienced Master Gardeners. There are several advantages in retaining volunteers. Volunteers with established knowledge who "know the ropes" serve as spokespersons for the program to recruit additional volunteers and as mentors for new class members. Since 1980, Master Gardeners in Johnson County, Ran., have served the 300,000 population base of the southwestern Kansas City suburban area through the county extension horticulture program. About $35 \%$ of the members of the first classes are still active volunteer participants after 10 years. Retention is encouraged by emphasizing that volunteer time is an opportunity for continued learning, rather than a "payback" for training received. An advisory board and committee structure encourages "ownership" of the program, and an advanced training program is offered to retained volunteers. Developing ideas for quality volunteer activities is continuously stressed. As new volunteers start the program, their abilities and skills in nonhorticultural areas that may be useful are assessed, such as woodworking, photography, speaking, leadership, and art. Applicants are screened to limit class size to 20 to 25 participants.

${ }^{1}$ County extension director, Johnson County Cooperative Extension Office, 1205 E. Santa Fe, Olathe, KS 66061 .

${ }^{2}$ Professor.

Department of Horticulture, Kansas State University, Manhattan KS 66506-4002. Contribution no. 91-388-E of the Kansas Agricultural Experiment Station. Mention of trademark, proprietary product, or vendor doer not constitute a guarantee or warranty and does not imply its approval to the exclusion of other products or vendors that also may be suitable.
$\mathrm{T}$ he Master Gardener program was started in 1972 in Seattle to assist local extension program efforts in horticulture (Roberts, 1982). The program now has been duplicated in $>45$ states (Barton, 1988). Although there have been minor program modifications by individual states and counties, the general concept is to provide a comprehensive basic training program for individuals interested in horticulture, with an expectation that they will volunteer time throughout the year to assist in extension educational programs.

The Kansas Master Gardener (MG) program was first initiated in 1980 in Johnson County, Kan., which is located in the southwestern suburbs of Kansas City and has a population base of $\approx 300,000$. The program consists of a 40 $\mathrm{h}$ basic training course of comprehensive horticulture with on-site instruction provided by Kansas State Univ. faculty, local extension agents, and other agency specialists. Inperson instruction with a limited class size of 20 to 25 participants emphasizes quality rather than numbers. After the initial classes were trained andvolunteer activities for the year were completed, program participants kept "coming back for more." It then was decided that retention of MG trainees should be emphasized for future years' activities.

Retention of MG volunteers offers several advantages for the program. Retained volunteers have increased horticultural knowledge and experience. In addition, MG volunteers serve as "walking advertisements" for the program, so recruitment of future classes of volunteers is easy. Returning MGs also serve as mentors or examples for new class participants to encourage their rapid involvement in the program. This is done through an organized mentor program that purposely mixes and retains volunteers in various activities. The Johnson County MG program encourages retention ofvolunteers for future years. About 35\% of the 38 Master Gardeners trained over a decade ago are still actively volunteering time to the program.

Retention of MGs is accomplished in several ways. Perhaps the most important is by discouraging volunteers from thinking of their hours as a "payback" for their basic training. Volunteer hours are emphasized as opportunities for continued learning, relating the MG volunteers to an ongoing learning group. As a result, the volunteers want to continue to learn and participate rather than stop when the hours are paid back.

The first orientation class for new participants promotes a relationship with the university and the local extension program. This orientation stresses getting acquainted with each other so that camaraderie develops among class members as well as a friendly "competition" among classes. New class participants spend a short time learning about "partner" class members, then introduce their partners to the rest of the group. Agents and a few experienced MG volunteers take notes during this session, making a record of special skills and abilities that new class participants have, so that these special abilities in nonhorticultural skills, such as woodworking, photography, artistic creativity, leadership, and speaking or teaching experience, can be recognized immediately. An emphasis is then placed on encouraging use of these abilities and linking new volunteers with experienced MG volunteers with similar interests.

An advisory board and committee structure provide ownership of the program by the experienced volunteers. Retained volunteers develop a curriculum for advanced 
training; continued participation in the MG program requires additional hours of training and structured volunteer time.

Advanced training consists of a combination of classroom sessions and tours, field days, and similar events. An emphasis is placed on accumulating a list of meaningful volunteer opportunities that point out the diversity of opportunities. Thus, the potential activities are viewed as useful, valuable, and needed rather than just opportunities to put in some hours. Community service and service to special populations become important parts of the volunteer activities. Volunteer activities in the Johnson County program are many and varied. MG volunteers conduct a speakers' bureau, problem-solving hotline, demonstration vegetable and perennial flower gardens, diagnostic clinics school programs, horticultural therapy, information-sharing at garden shows and public events, a fall "Lawn Fair" public event, and similar activities.

As Master Gardener programs evolve in many states each will have different emphases and objectives. The Johnson County program has chosen to emphasize quality participants and activities and retaining that quality over many years.

\section{Literature Cited}

Barton. B. 1988. Becoming a master gardener. Flower and Garden Oct.-Nov. p. 52,58-59,64-65.

Roberts, R. 1982. Master gardener: Helping others to grow. The Family Food Garden, Jan. p. 36-43. 